\title{
BOCA DO INFERNO \\ LITERATURA X HISTÓRIA: UMA INTERPRETAÇÃO DO PROCESSO DE CRIAÇÃO DE ANA MIRANDA
}

\author{
Hell's mouth. \\ Literature x History: An estabilishment process of interpretation Ana de Miranda
}

\begin{abstract}
Denis Pereira Martins
Doutorando em Letras pela Universidade Estadual de Londrina, iniciado em 2012. Mestre em Letras na Universidade Estadual de Londrina, pesquisador/bolsista pela CAPES. e-mail: denis.martins@sesipr.org.br
\end{abstract}

\begin{abstract}
RESUMO: Ana Maria Nóbrega Miranda teve seu lançamento no mundo literário com um livro de poesias intitulado Anjos e demônios (1978), entretanto, passou a ter visibilidade literária como romancista no final da década de 80, com o lançamento de Boca do Inferno. Trata-se de uma biografia romanceada do poeta Gregório de Matos, traduzida para mais de vinte idiomas. A obra tornou-se um clássico respeitado no campo da literatura. Subsidiada por leituras e mais leituras de textos do Padre Antônio Vieira e Gregório de Matos, a obra possui como cenário Salvador, no final do século XVII. Atenta à riqueza da linguagem empregada, utiliza-se de palavras vulgares para fazer juz a Gregório de Matos, apelidado como Boca do Inferno. Neste romance, de maneira crítica, Miranda visa mostrar uma terra marcada pela libertinagem, corrupção e luta pelo poder, retoma uma época em que o país se resumia em governantes corruptos e povo sem voz, sem autonomia. Dentro de sua proposta de literatura, o autor torna-se um historiador, um pesquisador. Utilizando-se do novo Romance Histórico, produz narrativas que focalizam acontecimentos integrantes da história oficial e, por vezes, definidores da própria constituição física das fronteiras brasileiras e também aquelas que promovem a revisão do percurso desenvolvido pela história literária nacional. Esse fazer literário, muito bem recebido pelo mercado editorial brasileiro, faz de Ana Miranda uma autora com um estilo único e recorrente. As vozes são múltiplas: onde acaba Vieira e começa Ana Miranda, onde é Gregório de Matos, ou o que restou dele em nossa memória?
\end{abstract}

Palavras chaves: Romance Histórico, Ana Miranda, Boca do Inferno, Mercado, Metaficção

ABSTRACT: Ana Maria Nobrega Miranda had its launch in the literary world with a book of poetry titled Angels \& Demons (1978), however, started to have literary visibility as a novelist in the late 80's with the release of Boca do Inferno. This is a romanticized biography of Gregorio poet, translated into over twenty languages. The book became a classic respected in the field of literature. Subsidized by readings and more readings of texts by Father Antonio Vieira and Gregorio, the work has as a backdrop Salvador, in the late seventeenth century. Aware of the richness of the language used, it makes use of vulgar words to do justice to Gregorio, dubbed as the Hellmouth. In this novel, critically, Miranda aims to show a land marked by licentiousness, corruption and power struggle, it takes a time when the country came down on corrupt rulers and voiceless people without autonomy. Within its literature proposition, the author becomes a historian, a researcher. Using the new Historical Romance, produces narratives that focus on members events of official history and sometimes defining the very constitution of Brazilian borders as well as those that promote the revision of the route developed by national literary history. This make literary, very well received by the Brazilian publishing market, Ana Miranda makes an author with a unique style and recurrent. The voices are manifold: where it ends and begins Vieira Ana Miranda, where Gregorio, or what's left of it in our memory?

Keywords: Historical Romance, Ana Miranda, Hellmouth, Market, Metafiction 


\section{Introdução}

Ana Maria Nóbrega Miranda, mais conhecida apenas como Ana Miranda, é uma romancista brasileira, nascida em 19/08/1951, em Fortaleza (CE) e criada em Brasília. Além de romancista, Ana Miranda escreveu poesias, desempenhou um único papel como atriz no filme Como era gostoso o meu francês. Com o passar dos anos, Miranda foi ganhando espaço e reconhecimento, como resultado, passou a ser reconhecida mundialmente, sendo escritora visitante em universidades como Stanford e Yale, nos Estados Unidos, e representou o Brasil perante a União Latina, em Roma. Atualmente, a autora publica textos, semanalmente, como colunista do jornal online O Povo, é colaborada da revista Caros Amigos e do Correio Brasiliense.

Este artigo se trata de uma discussão inicial sobre meu objeto de pesquisa no Doutorado em Letras (Universidade Estadual de Londrina - UEL), a obra Boca do Inferno, publicada por Ana Miranda em 1989. Esta autora tem como característica marcante uma preocupação minuciosa para com a linguagem, valorizando o brasilianismo, o que é natural e peculiar de sua nação ou, ainda, de determinada época representada em sua obra, mesmo o que fosse pertencente a uma época que não vivera. Esta última característica é essencial para essa discussão: Costa Lima (2006) alerta para o fato de o ficcional não se limitar à literatura, nem a literatura operar apenas através do discurso ficcional.

Em Boca do Inferno (1989) essa relação é evidenciada, uma vez que a autora constrói sua obra a partir de um amplo processo de pesquisa. Uma época em que o país se resumia em governantes corruptos e povo sem voz nem autonomia é retomada. A informação vem tanto da literatura quanto do discurso histórico. Esta inter-relação faz com que o narrador e utilize tanto de recursos da literatura quanto da história narrativa. Neste sentido, o narrador transita entre o mundo da história e o da literatura, mudando de posição de acordo com a focalização dada a Gregório de Matos (artista e indivíduo social e político). A ficção é o seu espaço de expressão, de liberdade criativa, no qual cabem as colagens, os cortes, a invenção, a distorção de personalidades e da própria história. 


\section{O Romance Histórico}

O Romance Histórico surgiu no início do século XIX e tinha como característica a reconstrução dos costumes, da fala e das instituições do passado. Ele mistura história e ficção, reconstruindo ficticiamente acontecimentos, costumes e personagens históricos. Para tanto, serve-se do enredo e de personalidades notáveis, tendo como pano de fundo a história ou os personagens capazes de transportar os leitores ao passado sem ser fiel a ele.

O primeiro romance histórico da literatura universal foi Waverley (1814), de Sir Walter Scott; mas o que serviu de modelo a todos os outros, foi $O$ Coração de Midlothian (The Heart of Midlothian, 1818) do mesmo autor. O maior de todos os romances históricos foi Guerra e Paz (Voina i mir, 1869), de Tolstoi.

Popularizado, o romance histórico rapidamente se expandiu pelas literaturas ocidentais e, desde então, tem colhido um número crescente de leitores e escritores. Devido a essa popularidade, temos hoje diversos tipos de romances históricos amplamente espalhados em um sistema literário que vai da literatura de massa até a literatura erudita. Tamanha diversidade postula a existência de três modalidades distintas de romance histórico, tendo como parâmetro de identificação a relação da literatura com a história. Dessa forma, teremos o "romance histórico tradicional", mais conhecido pelos leitores adeptos do romance histórico, aqui a história é o cenário para o exercício da ficção. Neste caso clássico de romance histórico, a relação entre literatura e história tem uma fronteira bem delimitada que não deve ser ultrapassada. 0 romancista tem consciência de seu papel na redação do romance, o que o impede de atribuir a si mesmo o status de historiador. O historiador deve compreender o romance como uma fantasia criada a partir de fatos históricos, respeitando a obra literária como arte. Dá-se isso porque os historiadores, conforme explicita Peter Burke, objetivavam elaborar "narrativas de grandes eventos e os feitos dos grandes homens", enquanto os romancistas aceitavam as interpretações dos historiadores como verdadeiras, adquirindo licença "para 
inventar personagens menores, ilustrando os efeitos de grandes mudanças históricas num nível local ou pessoal” (BURKE, 1997, p. 112).

Outra modalidade de romance seria "romance histórico revisionista" em que a história seria reescrita através da ficção. Nesse caso há uma intensa troca entre a literatura e a história. Colocam-se aqui as revisões históricas que buscam subverter as versões da história oficial, enquanto de outro lado está a liberdade do romance para preencher as lacunas de documentação da pesquisa histórica. Romancista e historiador passam a ser consortes engajados na busca de uma verdade maior que foi perdida ou ocultada. Literatura e história se confirmam mutuamente em termos de valores e veracidade.

A terceira e última modalidade histórica seria aquela que desvela 0 caráter narrativo da história, recusando os pactos de proximidade que sustentam as divisões entre os dois discursos, a ela dá-se o nome de "metaficção historiográfica". Dividir o território da narrativa entre ficção e história, ou unir forças para subverter o estabelecido não são mais suficientes nessa modalidade literária, como analisa Linda Hutcheon, a literatura e a história agora "partilham a mesma postura de questionamento com relação ao uso comum que dão às convenções narrativas, à referência, à inserção da subjetividade, a sua identidade como textualidade e até seu envolvimento na ideologia" (HUTCHEON, 1991, p. 142). Aqui, a verdade da história passa a ser plural e o romance se ocupa dos limites de toda e qualquer representação. Dessa forma, o valor da narrativa, histórica ou literária, está na verdade do que diz e na consciência da forma que usa para dizer essa verdade. A metaficção reconhece a história e a literatura como construções discursivas, o que possibilita reescrever o passado como ficção e a ficção como passado.

Lukács (1966) também estabelece divisões para o romance histórico. Ele aponta três fases principais no seu desenvolvimento, o que o tornaria didaticamente mais compreensível. Para Lukács, portanto, há uma parte reconhecida como clássica, do início do século XIX, estabelecida por Walter Scott que, como nenhum outro, soube manter um diálogo entre presente e passado, fazendo derivar da singularidade histórica a excepcionalidade na atuação de cada personagem. Quanto à especificidade da formulação do 
romance histórico, ele dá a entender que todo romance pode ser histórico, Lukács responde textualmente que ela não existe. Ele adverte que a tradição "realista" de composição do romance procede do tratamento do presente e do passado de um objetivo igual: "plasmar em forma narrativa a totalidade de um nexo vital e social” (LUKÁCS, 1966, p. 299). Retira desse princípio sua conclusão sobre o tema:

se poderia reparar todos os problemas de forma e de conteúdo do romance sem se deparar com uma única questão que fosse essencial e que pertencesse somente ao romance histórico. O romance histórico clássico surgiu do romance de sociedade e, enriquecendo-o e elevando-o a um nível superior, se incorporou a ele. Quanto mais elevado seja o nível dos romances históricos e dos romances de sociedade do período clássico, menores serão entre eles as verdadeiras distinções de estilo (LUKÁCS, 1966, p. 299).

Lukács, defende que o romance histórico se caracteriza pela articulação do gênero textual com o seu tempo de produção e, em sua sequência estrutural. Afirma que a ficção histórica não deriva do presente ou do passado, mas reforça a necessidade do compromisso do escritor com chamada verdade histórica, isto é, a vida do povo, o que corrobora com as ideias machadianas sobre o que devia ser importante no fazer literário:

Quando um escritor tem suas raízes profundamente ancoradas na vida do povo, quando acredita a partir desta íntima familiaridade com os problemas destacados da vida popular, é capaz de alcançar as verdadeiras profundidades da verdade histórica, inclusive quando dispõe apenas de uma "falsa consciência". Tal sucede com Walter Scott, com Balzac, com Tolstoi (Idem, p. 343).

Para Lukács, portanto, a definição de romance histórico não está centrada necessariamente na ênfase ao passado em detrimento do presente. A questão reside no discurso que a obra traduz, ou seja, na própria articulação que o gênero estabelece com seu tempo de produção. Reafirma-se aqui, por meio das palavras do teórico, que a relevância existente na classificação de um 
romance como histórico, ou não, está nas nuances que dão o tom, o colorido ao dado ao período estabelecido para a narrativa, que não necessariamente terá sua história marcada em um ponto do passado.

Para que um romance seja considerado histórico, contudo, não é necessário que nele haja referência a episódios factuais, verídicos. Se esse critério fosse seguido, a grande maioria dos romances seria histórico. No entanto, a redação de um romance de cunho histórico requer, usualmente, que seu autor trabalhe em pesquisas documentais e fontes históricas, o que pode induzir alguns leitores a se esquecerem de que estão diante de uma obra literária e não de pesquisa histórica.

Essa confusão do leitor e, muitas vezes da crítica, pode provocar exigências ao escritor, que não tem compromisso com a história propriamente dita, mas sim com a sua ficção, ambientada em um momento que remonta ao real, reconhecido pelos historiadores, e por quem já ocupou os bancos escolares em aulas de história do Brasil e do mundo. Alguns escritores não se atêm apenas aos fatos ocorridos em um dado momento, eles também detalham lugares, pintam o cenário da ação de maneira, por vezes, tão realista que contribui para a confusão entre ficção e veracidade. Contudo, uma obra capaz de levar a reflexão de fatos ocorridos em momentos mais, ou menos remotos é capaz de sacar o leitor de sua dormência histórica, trazendo-o a luz da reflexão.

Em relação a tais proposições sobre a importância reflexiva atribuída ao romance histórico, Lukács conclui que se trata de um gênero afeito a corrigir a "falsa consciência". Objeto do que classifica como período de decadência, compreendido na segunda metade do século XIX, uma "falsa consciência" que leva, na ficção, ao abstracionismo ou ao isolamento entre as partes. O romance torna-se histórico toda vez que, ao relacionar presente e passado, justamente em momentos de crise e incerteza como esses, corrige "as teorias falsas, os prejuízos literários" (Idem, p. 299).

O que enseja o uso do adjetivo histórico em um romance é a presença da história como parte constitutiva da obra, o que significa que sem a presença 
daqueles personagens e sem os sem os episódios conhecidos e reconhecidos como históricos o romance não se encaixaria no patamar de romance histórico.

\section{O Romance Histórico de Ana Miranda}

O fazer literário percorreu através dos tempos um longo caminho de transformações e evoluções. A literatura reflete as sociedades de cada tempo, assim como a sociedade reflete sobre a literatura. Da literatura clássica à moderna, foram muitas as transformações, algumas permanentes, outras de cunho mais efêmero, e os estudos dos gêneros sempre se debruçaram sobre as novidades textuais a fim de explicá-los e registrá-los no tempo e espaço. $\mathrm{Na}$ tentativa de se estabelecer o que seria o fazer literário, por meio das distinções entre as diferentes classificações que são dadas à cultura, o viés teórico está quase sempre na retaguarda da dinamicidade social. As teorias se voltam à estrutura do texto, permitindo as discussões sobre valor do objeto de arte e sobre os elementos característicos de cada gênero, que se transformam com o passar do tempo. A crítica e a teoria literária ainda se pautam em conceitos postulados por Aristóteles, em sua Poética, para só então se voltarem às novas práticas do fazer literário, sobretudo com seu crescente aumento no mundo eletrônico, influindo na leitura, na escrita e no consumo.

A autora em discussão se debruçou sobre os livros, desenvolvendo análise e estudo respeitável, o que possibilitou que recriasse momentos históricos da literatura brasileira, reavivando e enfatizando a linguagem arcaica, consumida pelo tempo.

Em entrevista ao Blog da Companhia, por Sérgio Sant'Anna, o blogueiro faz o seguinte questionamento "Você ter ido morar de novo no Ceará tem a ver com seus romances ligados ao Brasil e à terra ou é justamente o contrário: você, morando num lugarejo de praia, acaba escrevendo sobre a grande cidade?" destacamos excerto que ilustra bem o perfil da escritora:

Estou sempre distante de minha realidade e buscando distância de mim mesma, se é que isso é possível. Não escrevo sobre mim, como dizia o Guimarães Rosa. No Outro é que encontro inspiração. E mesmo me entranhando de toda uma cultura peculiar à terra, 
continuo vivendo a distância literária. $\mathrm{O}$ que ando escrevendo por aqui tem mais relação com minhas leituras e com minha imaginação do que com a realidade que me cerca, como sempre. É um processo interior. Busco experimentar outras vivências, outras falas, outros comportamentos literários, é o meu jeito de ser. (SANT'ANNA, 2013)

A ação discorre em Salvador, uma cidade de caos e desordem, é a recriação de uma época turbulenta centrada na luta pelo poder entre o governador Antônio de Souza de Menezes, o Braço de Prata, e a facção liderada por Bernardo Vieira Ravasco, da qual faziam parte o padre Antônio Vieira e o poeta Gregório de Matos. Ana Miranda recria esse ambiente em sua ficção, utiliza da vida e produção de Gregório de Matos, padre Antônio Vieira, entre outros, para compor sua escrita. Anne Macedo discute o processo de criação do texto literário a partir de pesquisa histórica, como realizado pela autora: "as fontes podem ser combinadas ou recombinadas na fantasia e no delírio do autor: este processo é parte do mecanismo criativo, e [...] o que está em foco é a tensão entre a liberdade ficcional e a verdade histórica" (2015, p.16). Tal obra transforma o modo de se lidar com as fontes históricas e promove o questionamento do processo de produção artística. Cada personagem do romance ocupa um lugar específico em cada formação social, como afirma Gebra e Gartner: "há personagens que ocupam o eixo do poder político, do poder eclesiástico, do poder econômico, e há aquelas que ficam à margem das relações estabelecidas, que seriam os revolucionários, os bêbados, as prostitutas e, de forma geral, as mulheres”. (2008, p.397). Esse discurso silenciado pela História oficial é enfatizado por Ana Miranda. Segundo Jacques Le Goff (1990), o tempo da narração constitui um local de observação particularmente interessante. Esse tempo como recuperação da memória coletiva. Lukács define-o como um universo específico generalizante em que os personagens seriam tipos bem marcados, sínteses do geral e às figuras históricas eram relegados papéis secundários. Contrariando à crítica, é interessante notar que esses fatos não ocorrem neste objeto: o universo é específico e bem construído, fruto de pesquisas, os personagens são complexos e, ainda que históricos, protagonistas para o enredo. 
A escrita é múltipla: historiografia, ficção, biografia, crítica literária, tudo em um trabalho baseado em pesquisas e no recurso das fontes. A ficção se apresenta como um panorama histórico e literário da época barroca. É quando partimos aos questionamentos do papel do autor na escrita de um romance. $O$ que é um autor? Para Foucault (1992), o autor seria então uma espécie de índice de catalogação na ordem dos discursos, uma assinatura que confere autoridade ao texto. Pode-se afirmar que a força dessa referência se sustenta em três bases que se relacionam: escrita, autoria e obra, que seria o resultado do trabalho de escrita firmado por uma marca pessoal. As vozes são múltiplas: onde acaba Vieira e começa Ana Miranda, onde é Gregório de Matos, ou o que restou dele em nossa memória? Em alguns trechos analisados se nota a semelhança do conteúdo relatado e consegue-se perceber como se dá de fato esse processo de construção literária a partir da pesquisa.

Essa é uma característica comum à escrita do Novo Romance Histórico, tendência surgida a partir dos anos 70 no século XX. Tal escrita prevê a recuperação e a escrita da história nacional, que é revisitada em seus diferentes momentos. A leitura do conjunto dessa produção revela, pelo menos, a existência de dois caminhos que, preferencialmente, têm sido observados pelos autores: de um lado, situam-se as narrativas que focalizam acontecimentos integrantes da história oficial e, por vezes, definidores da própria constituição física das fronteiras brasileiras; de outro, aquelas que promovem a revisão do percurso desenvolvido pela história literária nacional, grupo do qual Ana faz parte. A organização de todos esses fios parece guardar uma proximidade com uma atitude de ficcionista investigativo, isto é, romances que recriam o itinerário das personalidades protagonistas com riqueza de detalhes que, se por um lado resultam de pesquisas, por outro, no caso dos personagens literários, ativam, em suas reconstruções, o influxo da mais recente crítica biográfica, privilegiando uma reelaboração mais afastada daquilo que é tido como verdade histórica.

Morais (2003) explica que há em Boca do Inferno uma síntese do Brasil do presente associada a um Brasil do passado. Uma ideia de que o domínio econômico e cultural de nosso país permanece em mãos impróprias e não do 
legítimo brasileiro. A ideia de colônia foi transformada, entretanto, ainda permanece viva em nosso solo. Existe no coração do brasileiro o sentimento de colonizado, "mas não continuamos como Gregório de Matos, com um pé lá e outro cá, temos agora os dois pés no Brasil, porém os sapatos ainda são importados." (MORAIS, 2003) Morais, defende que a maior qualidade do romance está na tentativa de formar uma identidade brasileira, ao mesmo tempo que propõe a sua desintegração. A autora esclarece que romance nada mais é que o resultado de sentimentos presentes em uma determinada época. “(...) o romance publicado em 1989 por Ana Miranda, parece unir o que W.Mignolo considera como uma necessidade humana de" conservar e transmitir o passado" a uma necessidade de "projetar sua energia criativa em diferentes formas." (MORAIS, 2003)

\section{Ana e o sucesso de mercado}

De acordo com Macedo, foram vendidos 50 mil exemplares, o que elevou Miranda ao topo do núcleo literário, mesmo assim, a maneira em que este foi escrito não escapou de duras críticas, como a de Luciana Stegagno Picchio, de que este retorno ao passado é totalmente desnecessário, sem nenhuma razão concreta. O romance Boca do Inferno surgiu em meio a muitas controvérsias e mudanças dos paradigmas literários, com uma escrita que consolidou o seu estilo, possibilitou que Ana Miranda continuasse com novas posteriores publicações. Contudo, a sua maioria continuou com a mesma fórmula de seu primeiro romance, explorando aspectos históricos, mesclandoos com a biografia de escritores brasileiros reconhecidos - Augusto dos Anjos, Clarice Lispector e Gonçalves Dias. Nenhuma outra obra da autora chegou perto de causar o impacto de Boca do Inferno. Acreditamos que impulsionada pelo sucesso da primeira tentativa, pelo volume representativo de vendas, pelo reconhecimento enquanto autora literária, Miranda arriscou-se em repetir a receita, que já não era mais uma novidade.

Num dos primeiros artigos publicados na imprensa, 0 Boca do inferno é apresentado, dias antes do seu lançamento, como "uma joia rara, trabalhada em sua 
ourivesaria com devoção de monge, pesquisada com rigor de cientista, e brilhante em seus resultados como as mais finas pedrarias". A matéria faz referência ao estilo da autora, trata-a como a maior revelação dos últimos anos das letras nacionais, elogia o seu procedimento e suas escolhas artísticas - a revisitação do século XVII brasileiro - exaltando o seu talento e comemorando o ingresso do país no "romance histórico moderno", gênero que vinha adquirindo conotação e importância na literatura internacional desde a publicação de Memórias de Adriano, de Marguerite Yourcenar, de 1951, e consagrando-se nos anos 1980 com Umberto Eco e José Saramago. (MACEDO, p.4)

Em entrevista ao jornalista Carlos de Souza, este questiona a opinião de Ana Miranda sobre o sucesso de venda de mais de 40 mil exemplares na época do lançamento do Boca do Inferno, ainda mais num país como o Brasil, tido como de poucos leitores, em que livro seria um objeto de baixo consumo. A autora afirma ser um mistério, entretanto, crê que este é o resultado de todo o esforço que teve para escrevê-lo, durante dez anos. Além disso, a presença de Gregório de Matos e de padre Antônio Vieira podem ser um chamariz da atração e aceitação por parte dos leitores.

Enfim, percebemos que Ana Miranda "aproveitou-se" do momento metamórfico que havia na literatura para lançar um romance que fugia aos padrões existentes e deu certo. Consagrou-se como literária, ganhou prêmios, foi reconhecida, inclusive, em outros países, o que não a livrou de críticas e acusações de não autenticidade. Apesar de continuar no ramo literário e possuir outras publicações, Boca do Inferno continua como o livro que a representa enquanto escritora, o livro que a fez ser escritora. As outras obras da autora seguem esta estrutura ficcional, sendo este tópico para outras discussões. 


\section{Referências}

BURKE, P. As fronteiras instáveis entre história e ficção. In: AGUIAR, F. Gêneros de fronteira: cruzamentos entre o histórico e o literário. São Paulo: Xamã, 1997.

COSTA LIMA, Luiz Costa. História, ficção e literatura. São Paulo: Companhia das Letras, 2006.

FOUCAULT. Michel. O que é um autor? Lisboa: Passagens, 1992.

GÄRTNER, Mariléia; GEBRA, Fernando. Entre espelhos, dobras e duplos: desconstruções discursivas em Boca do Inferno, de Ana Miranda. Jornada Internacional de Estudos do Discurso, 2008.

HUCTHEON, L. Poética do pós-modernismo. Rio de Janeiro: Imago, 1991.

LE GOFF, Jacques. História e memória - tradução Bernardo Leitão [et al.]. Campinas: Editora da UNICAMP, 1990.

LUKÁCS, Gyorgy. A teoria do romance. São Paulo: Editora 34, 1966.

MACEDO, ANNE. Ana Miranda na boca da crítica <observatoriodacritica.com.br/arquivos/publicacoes/annegreice/Ensaio\%20Anne\%20Greice.pdf > Consultado em 23/09/2015

MIRANDA, Ana. Boca do inferno. São Paulo: Companhia das Letras, 1989.

MORAIS, Eunice de Morais. Ficção e História no Romance Boca do Inferno. Dissertação de mestrado: <dspace.c3sl.ufpr.br:8080/dspace/bitstream/handle/1884/24349/D\%20-

\%20MORAIS,\%20EUNICE\%20DE.pdf?sequence=1> Consultado em 23/09/2015.

SANT'ANNA, Sérgio. Entrevista com Ana Miranda. Disponível em: <www.blogdacompanhia.com.br/2013/04/entrevista-com-ana-miranda> Consultado em 23/09/2015.

Recebido: 09/07/2015

Received: 07/09/2015

Aprovado: 29/07/2015

Approved: 07/29/2015 